\title{
Monetary Aggregates as Monetary Indicators
}

\author{
KEITH M. CARLSON and SCOTT E. HEIN
}

$\mathrm{T}_{\mathrm{H}}$

HE monetary aggregates are being relied upon more and more as indicators of the thrust of monetary policy actions on aggregate economic activity. ${ }^{1}$ To be useful as a monetary indicator, a monetary aggregate should satisfy at least two criteria. First, it must be sensitive to policy actions taken by the Federal Reserve - such as open market operations and changes in reserve requirements, the discount rate, and Regulation Q ceilings; it must not be sensitive to influences other than Federal Reserve actions. If the monetary aggregate is responsive to nonpolicy forces, it will provide erroneous signals as to the thrust of monetary policy. ${ }^{2}$

Second, a monetary aggregate should be both consistently and predictably related to the pace of economic activity. If it is not, changes in the monetary aggregate will not "indicate" what will happen to aggregate economic activity as a result of actions cur-

\footnotetext{
For a general discussion of monetary indicators, see Albert $\mathrm{E}$, Burger, "The Implementation Problem of Monetary Policy," this Review (March 1971), pp. 20-30.

2This criterion explains why many argue against the use of market interest rates as monetary indicators. See Albert $\mathrm{E}$. Burger, "The Implementation Problem ...." where he argues that market interest rates are poor monetayy indicators because they are sensitive to nonpolicy impulses, such as factors that affect the demand for credit.
}

rently being taken by monetary authorities.

Early this year, the Federal Reserve Board announced a redefinition of the monetary aggregates. In some cases, the differences between the old and new money measures are quite substantial. While the relationship between the old monetary aggregates and economic activity has received much attention in the economic literature, the usefulness of the new monetary aggregates as monetary indicators has yet to be examined in detail. This article reports some results bearing on this issue.

The analysis focuses primarily on the relationship of the new M1A, M1B, and M2 measures to economic activity. To provide historical continuity, the results are compared with those derived from analyses of the old M1, M2, and M3 aggregates.

\section{THE NEW MONETARY AGGREGATES}

Components of the new M1A, M1B, and M2 monetary aggregates are listed in table $1 .^{3}$ MIA is identical

\footnotetext{
3For a detailed description of the new monetary aggregates, see R. W. Hafer, "The New Monetary Aggregates," this Review (February 1980 ), pp. $25-32$; or Thomas D. Simpson, "The Redefined Monetary Aggregates," Federal Reserve Bulletin (February 1980), pp. 97-114.
} 
to old M1, except that it excludes demand deposits due to foreign commercial banks and official institutions. The new M1B aggregate, a broader transaction measure, is equal to $M 1 A$, except that it includes newly developed interest-bearing transaction deposits. These latter deposits include negotiable order of withdrawal (NOW) accounts, automatic transfer system deposit (ATS) accounts, and credit union share drafts. NOW accounts were legalized in certain New England states early in the 1970 s, and such legalization will extend nationwide as of December 31, $1980 .^{4}$ Commercial banks have been permitted to offer individual ATS accounts since November 1, 1978.

Chart 1 presents compounded annual rates of change of old M1, M1A, and M1B for the period II/ 1959 through IV $1979 .^{5}$ The chart shows that the exclusion of demand deposits held by foreign commercial banks and institutions has had little effect on the growth rates of the monetary aggregates. Growth rates of new M1A closely resemble those of old M1. Furthermore, the growth rates of M1A and M1B differ little prior to early 1974 and, although M1B growth usually exceeds that of M1A over the period I/1974 through III/1978, the disparity between these aggregates is quite small. It is only after the nationwide introduction of ATS accounts in late 1978 that the growth rates of these new aggregates show any marked divergence.

While the new M1A and M1B measures are similar in scope to old M1, the new M2 measure is quite different from old M2. In fact, the new M2 measure is more closely related to the old M3, which included savings and small time deposits of thrift institutions; old M2 did not include such deposits. Because the monetary aggregates are no longer differentiated on the basis of institutional considerations, old $\mathrm{M} 2$ does not have a counterpart among the new measures.

As shown in table 1 , there is essentially only one component of the old M3 measure - large time deposits (other than large negotiable CDs) at commercial banks and thrift institutions - that is not included

\footnotetext{
4.For a description of the New England experience with Now accounts, as well as a discussion of how their legalization will affect other parts of the country, see William N. Cox III, "NOW Accounts: Applying the Northeast's Experience to the Soththeast," Economic Review of the Federal Reserve Bank of Atlanta (September/October 1980), pp. 4-10; and Patrick J. Lawler, "NOW Accounts in the Southwest: A Break for Consumers, an Entry from S\&L's, and a Test for Banks" Voice of the Federal Reserve Bank of Dallas (October 1980), pp. $1-8$.
}

5The historical series for the new monetary aggregates begins in $\mathrm{I} / 1959$.

\begin{tabular}{|c|c|c|c|}
\hline Component & MiA & MiB & M2 \\
\hline Currency in circulation & $x$ & $x$ & $x$ \\
\hline $\begin{array}{l}\text { Denrand deposits at commercial } \\
\text { barks and thrift instifuilons } \\
\text { exclusive of deposits due to } \\
\text { foreign commercial banis and } \\
\text { officlal Institutions }\end{array}$ & $x$ & $x$ & $x$ \\
\hline $\begin{array}{l}\text { Now and ATS accounts and } \\
\text { credit union share dratts }\end{array}$ & & X & $x$ \\
\hline Overnight RPs & & & $x$ \\
\hline $\begin{array}{l}\text { Sayings deposits at commerclal } \\
\text { banks and thiff institutions }\end{array}$ & & & $x$ \\
\hline $\begin{array}{l}\text { Small time deposits (less than } \\
\$(100,000) \text { at connmercial banks } \\
\text { and thrift institutions }\end{array}$ & & & $x$ \\
\hline $\begin{array}{l}\text { Overnight Eurodollar deposits } \\
\text { issued by Carbbean branches of } \\
\text { nember banks and held by } \\
\text { U.S. nonbank residents. }\end{array}$ & & & $x$ \\
\hline Money market mutual fund shares & & & $x$ \\
\hline
\end{tabular}

in the new M2 measure. On the other hand, a number of the changes that have been made make new M2 even more comprehensive than old M3. In addition to the interest-bearing transaction deposits included in M1B, the new M2 measure also includes ovemight RPs at commercial banks, money market mutual funds, and overnight Eurodollar deposits issued by Caribbean branches of member banks and held by U.S. nonbank residents. ${ }^{6}$

Chart 2 depicts the compounded annual rates of change of new $\mathrm{M} 2$, old $\mathrm{M} 2$, and old M3. Growth rates of the new M2 and old M3 aggregates were similar from the II/1959 through II/1973 period; growth rates of old M2, on the other hand, generally were much slower than these aggregates. The similarity in the growth rates of old M3 and new M2 breaks down in late 1973, however, when overnight RPs, money market mutual funds, and the overnight Eurodollar deposit component of new M2 became increasingly popular.

WTinothy Q. Cook and Jeremy G. Duffeld, "Short-Term Investment Pools," Economic Review of the Federal Reserve Bank of Richmond (September/October 1980), pp. 3-23. The authors have recently argued that there are many other investment pools, similar to money market mutual funds, which should be included in the new M2 measure. 
Chart 1

Compounded Annual Rates of Change of MI(old), MIA and MIB

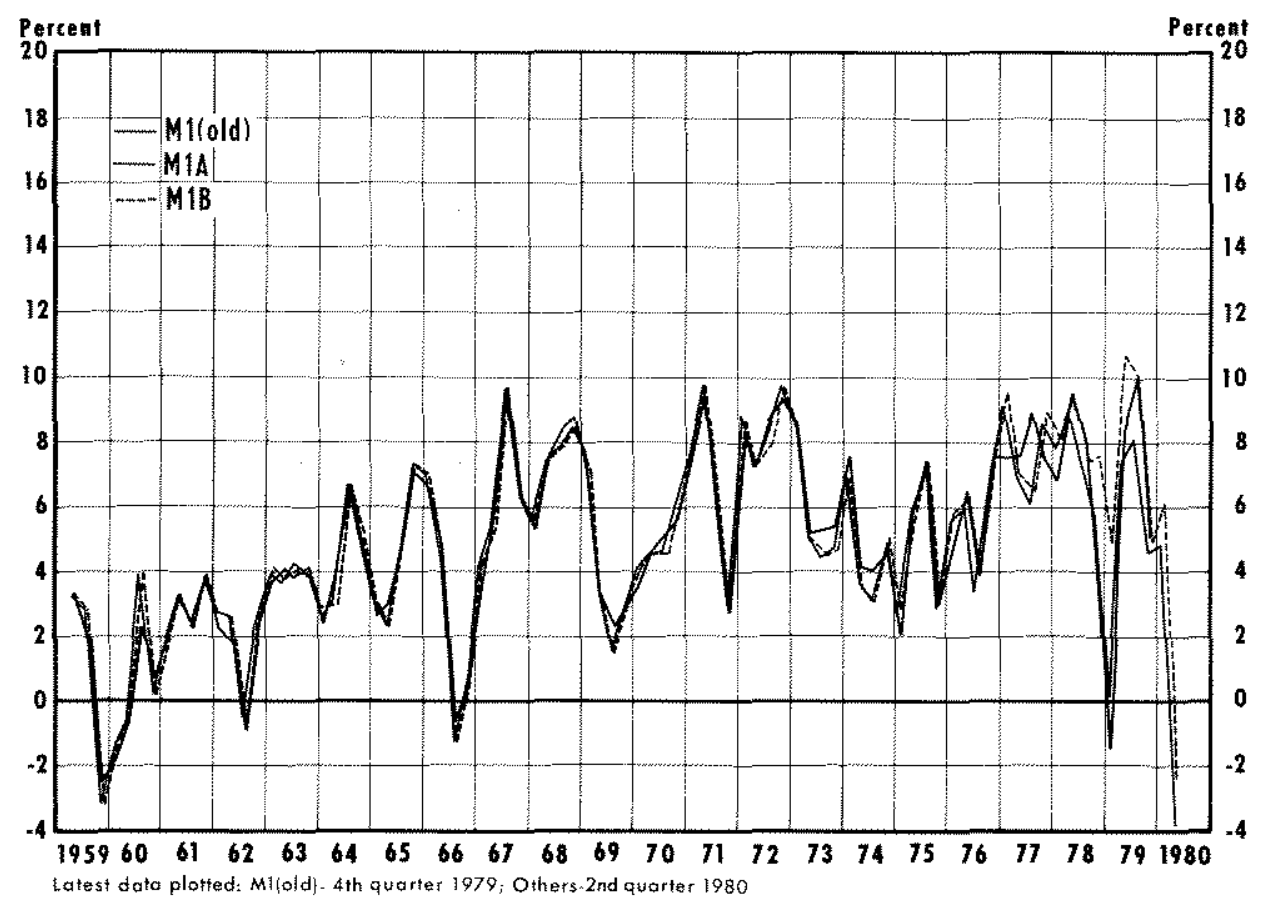

\section{Chort 2}

Compounded Annual Rates of Change of

$M 2$ (new), M2(old) and M3(old)

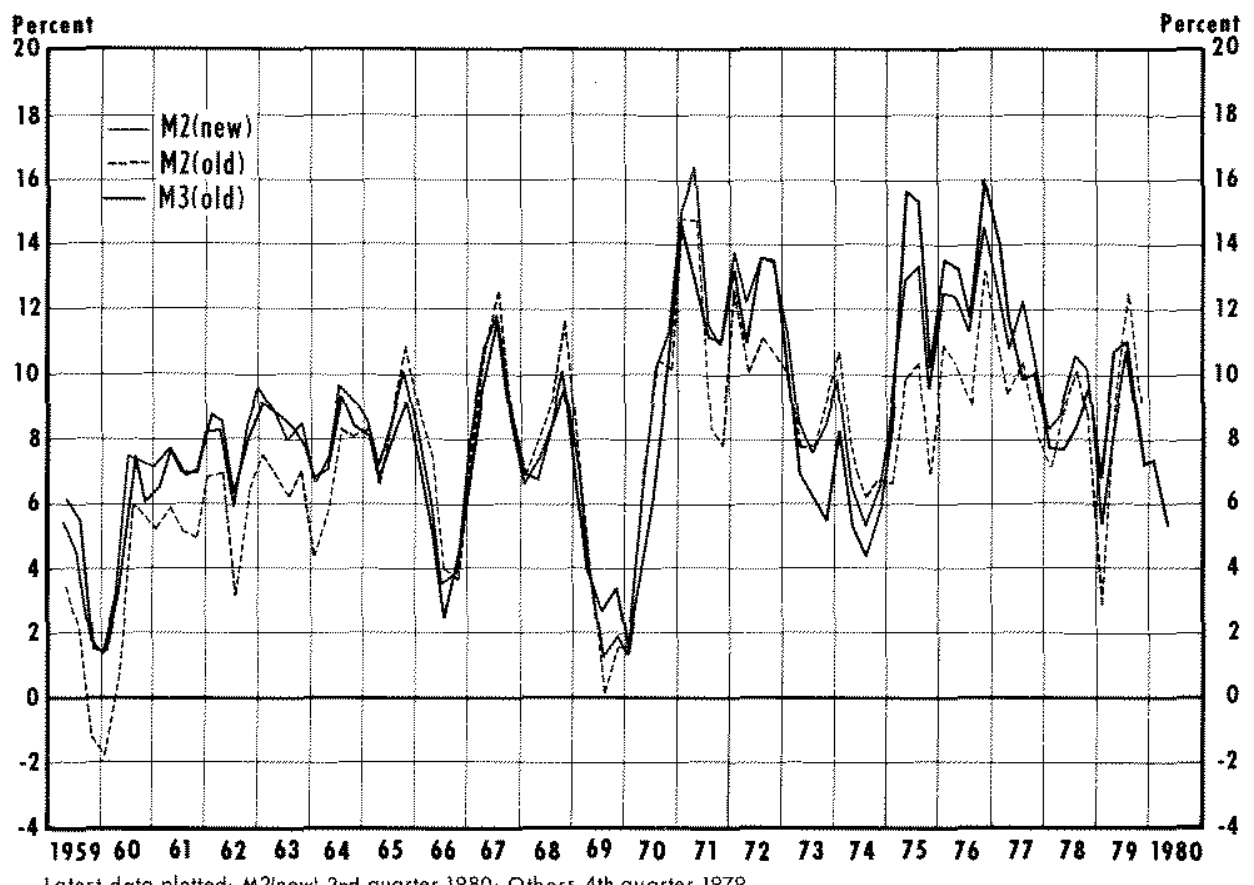

Latest data plotted: M2[newi-2nd quarter 1980 ; Others. 4 th quarter 1979 


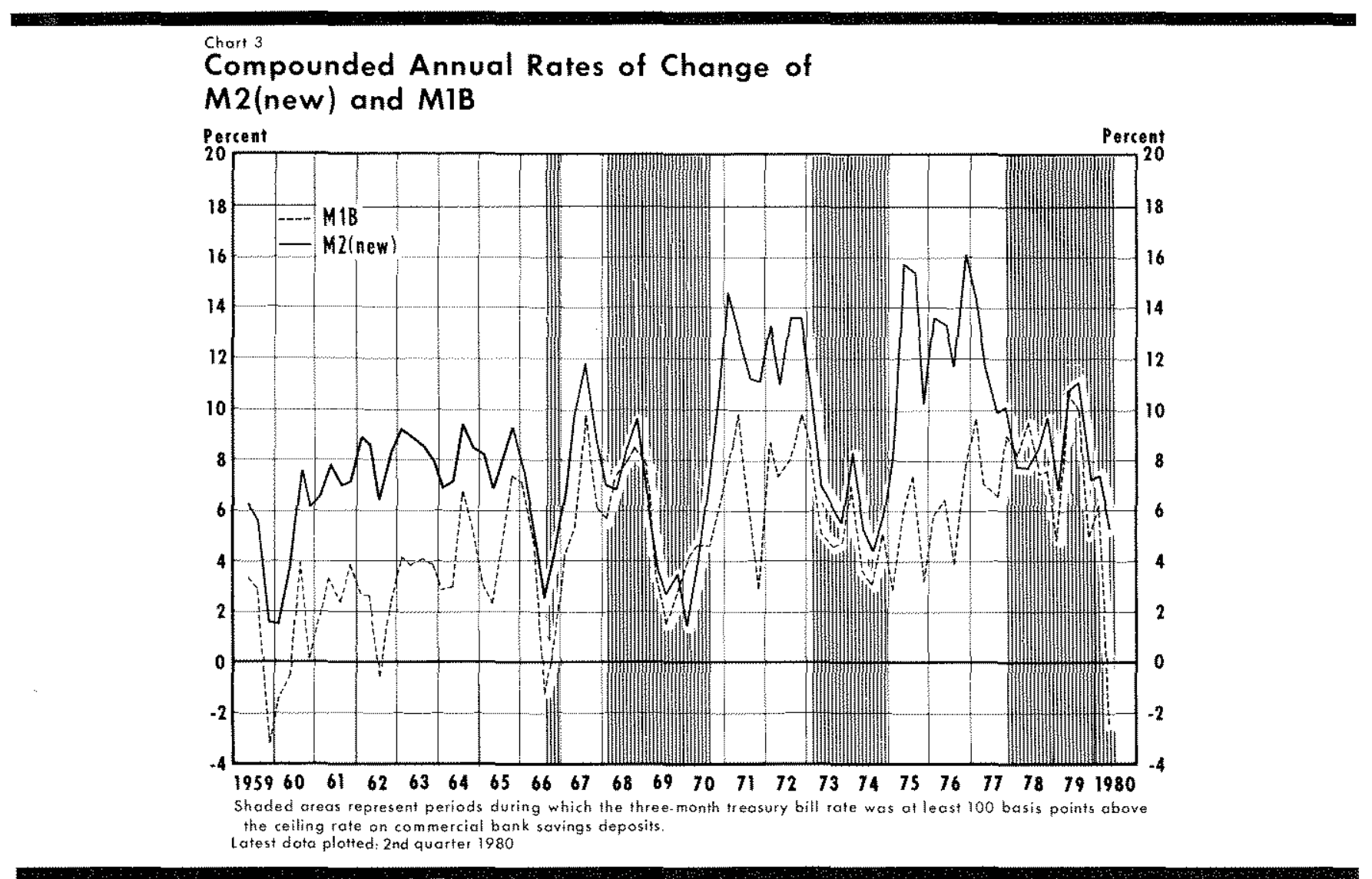

Finally, chart 3 presents the compounded annual rates of change of the new $M 1 B$ and M2 aggregates. This chart illustrates the differential growth rates of narrow versus broad money measures. ${ }^{7}$ Note the difference in average growth rates; new M2 growth is usually above that of $\mathrm{M} 1 \mathrm{~B}$. The average growth rate of new M2 over the II/1959 through IV/1979 period is 8.4 percent, compared to 5.0 percent for M1B.

The differential between the two growth rates sometimes varies. The chart indicates a definite pattern in the relative growth rates. Over the periods II/1959-IV/1965, III/1970-I/1973, and I/1975-I/1978, growth rates of new $\mathrm{M} 2$ are substantially above those of M1B. In the intervening periods, the differential between growth rates of these two aggregates is very small.

Historical experience indicates that the growth rate of the broad money stock measure is sensitive to the differential between market interest rates and Regulation $Q$ ceilings. This is clearly indicated by the

TMLA is excluded for simplification purposes; prior to late 1978 , quarterly growth rates of MIA were very similar to those of MIB (see chart 1). Further, while only the new aggregates are shown, old M1 and M2 display a similar pattern. shaded areas in chart 3 , which depict periods of two quarters or more during which the three-month treasury bill rate was at least 100 basis points above the ceiling rate on commercial bank savings deposits. ${ }^{8}$ Redefining this broader monetary aggregate has not made it insensitive to nonpolicy influences. Nompolicy factors that affect the supply or demand for credit and, as a result, change market interest rates will clearly influence the growth of new M2 just as they affected the growth of old M2 and M3. The sensitivity of new M2 to such nompolicy factors thus reduces its usefulness as an indicator of monetary policy actions.

\section{THE RELATIONSHIP BETWEEN ECONOMIC ACTIVITY AND THE MONETARY AGGREGATES}

The relationship between economic activity and the new monetary aggregates is investigated with

8The chart indicates that the most recent period of clisintermediation, IV/1977-11/1980, has not had the same effect in reducing new M2 growth relative to MIB as observed in previous periods of disintermediation. However, at least part of this phenomenon is explained by the rapid growth of overnight RPs and Eurodollar deposit holdings and, more recently, by money market mutual funds. 
reference to nominal GNP. Nominal GNP is chosen becuse this is the apparent chamel by which monetary policy variables directly affect the economy. ${ }^{9}$ The general form of the relationship to be estimated is:

$$
\dot{Y}_{t}=C+\sum_{i=0}^{R} m_{t} \dot{H}_{t-1}+\sum_{i=0}^{R} e_{i} \dot{E}_{i-1}+\mu_{t}
$$

where $\dot{Y}$ is the compounded annual growth rate of nominal GNP, $\dot{M}$ is the compounded annual growth rate of the given monetary aggregate, $\dot{E}$ is the com pounded annual growth rate of high-employment expenditures, and $\mu$ is a randon error term. ${ }^{10}$ This relationship is estimated using the new M1A, M1B, and $\mathrm{M} 2$ aggregates and the old $\mathrm{M} 1, \mathrm{M} 2$, and $\mathrm{M} 3$ measures. The relationships are estimated with the ordinary least squares estimation technique.

The investigation subjects the six different relationships to a number of statistical tests. The strategy is first to find the optimal lag structure for the different relationships over the sample period, III/1962 through III/1977. After investigating the in-sample stability of the relationships and the likelihood of simultaneous equation bias problems, these estimated relationships are then used to project nominal GNP over the postsample period, IV/1977 through IV/1979, to determine which relationship would have yielded the most accurate forecasts for this period. This period was chosen because of the divergent growth rates for the various aggregates, as shown in the preceding charts.

\section{Sample Period Relationships}

The first concern in estimating the general relationship given in equation (1) is to determine the appropriate values of $f$ and $g$, the number of lags on the monetary and fiscal variables. Lag values of 0 , 4 , and 8 were considered for each of the six relationships. Interestingly enough, F-tests for each of the equations indicated that the appropriate lag value was

\footnotetext{
"See Milton Friedman, "A Theoretical Framework for Monetary Analysis," in Milton Friedman's Monetary Framewotk. A Debate with His Critics, ed. R. J. Cordon (University of Chicago Press, 1974), pp. 1-63; and Charles $\mathrm{R}$. Nelson, "Recursive Structure in U.S. Incone, Prices, and Output," Journal of Political Economy (December 1979), pp. $1307-27$

10This relationship is similar to the original Andersen-fordan equation. Such a relationship has been estimated more recently by Keith M. Carlson, "Money, Inflation, and Economic Growth: Some Updated Reduced Form Results and Their Implications," this Review (April 1980), pp. 13-19. Usually, the relationship is estimated assumning that the lag coefficients lie along a polynomial of a given degree. No such constraints are imposed here.
}

4 for each of the separate monetary aggregates, as well as for the fiscal variable.

Table 2 provides the sample period coefficient estimates and summary statistics for the six different equations, where the relationships are estimated with ordinary least squares and four lags on the fiscal and monetary variables are assumed. There is very little difference between the sample period fit provided by the various aggregates. In all cases, the standard error of the estimating equation ( $\mathrm{SEE}$ ) is less than onethird the size of average GNP growth over the sample period (9.61 percent).

While the pattern of the distributed lag effects of both the fiscal and monetary variables is similar across equations, the size of the coefficients is clearly dependent on the comprehensiveness of the monetary aggregate employed. In general, the more comprehensive the aggregate, the smaller the size of any lagged monetary coefficient. The sum of the money coefficients is close to 1.0 for both M1A and M1B. ${ }^{11}$ On the other hand, the sum of the money coefficients for new $\mathrm{M2}$ is close to 0.7. Regardless of the aggregate used, the sum of the high-employment expenditures coeffcients is close to zero.

\section{Stability Tests}

A question to be considered with these estimation results is whether the relationships reported in table 2 are structurally stable (i.e. whether the regression coefficients change significantly with time). The hypothesis of structural stability was investigated with the use of the Chow test. The formal hypothesis tested is whether the regression coefficients estimated for the III/1967 through IV/1969 sample period differ significantly from those obtained for the same equation in the $\mathrm{I} / 1970$ through III/1977 period. The null hypothesis is that the coefficients are equal in each of these periods. The midpoint of the sample was chosen as the breakpoint because it maximizes the power of the test. ${ }^{12}$

Table 3 lists the F-statistics for each of the various equations. None of the cases considered provide evi-

\footnotetext{
11 The results reported for the narrow aggregates are similar to those found by keith M. Carlson, "Noney, Inflation and Economic Growth . ..." where a third degree polynomial with tail constraints was employed in the estimation.

1'See John U, Farley, Metvin Hinich, and Timothy W. Mcm Guire "Some Comparisons of Tests for a Shift in the Slopes of a Multivariate Linear Time Series Model, Joumal of Econometrics (Volume 3, No. 3, 1975), pp. 297-318.
} 
Table 2

Relationships Between GNP and The Monetary Aggregates

$$
\dot{Y}_{t}=c+\sum_{t=0}^{1} m_{1} M_{t-1}+\sum_{t=6} e_{t} \dot{E}_{t+1}+\mu_{t}
$$

(Sample Period, Il/1962-1l1/1977, absolute value of t-statistic in parenthesis)

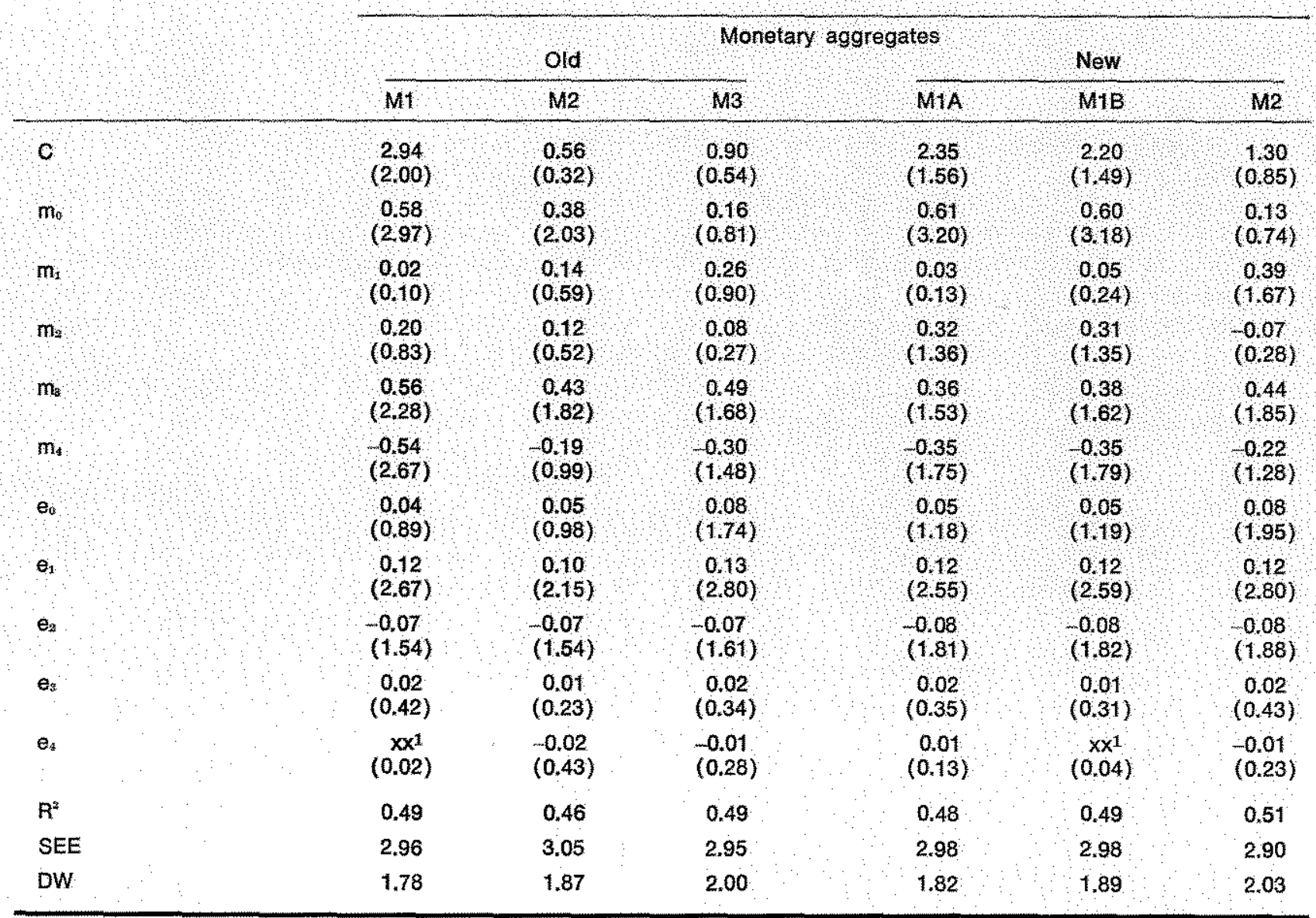

1less than 0.005

Table 3

Calculated F-Statistics for Test of Break In Relationships (III/1962-IV/1969 vs. I/1970-III/1977)

\begin{tabular}{|c|c|c|c|c|c|c|}
\hline & \multicolumn{6}{|c|}{ Monetary aggregates } \\
\hline & \multicolumn{3}{|c|}{ Old } & \multicolumn{3}{|c|}{ New } \\
\hline & M1 & $M 2$ & M3 & M1A & MIB & $\mathrm{M2}$ \\
\hline$F(11,39)^{1}$ & 1.52 & 1.11 & 0.64 & 1.64 & 1.62 & 0.61 \\
\hline
\end{tabular}

The 5 percent critical level is 2.05 ; the 10 percent critical level is 1.73 . 
dence to reject the null hypothesis at traditional levels of significance. ${ }^{13}$

\section{Simultaneous Equation Bias Tests}

A further question with regard to the estimation results reported in table 2 is whether or not they are subject to significant simultaneous equation bias. Equations such as those reported in table 2 can be estimated reliably with ordinary least squares methods only if the independent variables are exogenous. A major criticism of equations of this type is that the monetary aggregates are not exogenous with respect to $\mathrm{GNP}^{14}$

Sims has recently suggested a test to examine whether the independent variables in a distributed lag relationship, such as equation (1), can be said to be statistically exogenous. ${ }^{15}$ The test procedure involves adding leading values of the independent variables to the basic distributed lag equation. If the regression coefficients of the leading values of the

13 A break in the relationship in $1 / 1974$ was also considered. With the exception of the new $\mathrm{Mz}$ relationship, there is evidence, at traditional levels of significance, to siggest a break in all the relationships. With regard to the inability to reject the stability of the new M2 relationship, it should be noted that none of the separate subperiod money coefficients dif fered from zero.

The fact that all other equations hreak is evidence of the specification error. There appear to be two likely candidates for omitted variables. First, none of the relationships include a variable to capture the impact of the oil shock which occurred near 1974 . Second there is no variable to capture a shift in money demand if, as many argue, money demand shifted in 1974. (For example, see Stephen M. Coldfeld, "The Case of the Missing Money," Brookings Papers on Economic Activity (3:1976), pp. 683-730.)

Since we are primarily concerned with the coefficients on the money variables, either of these specification errors will cacse a problem only to the extent that the excluded vatiable is correlated with the indepenclent variables. It is only when such correlation exists that the estimated coefficients will be biased. Regardless of whether either or both of the above specification errors exist, it is unihely that this bias problen will result. Both of the suggested specification erors resulted because shock variables vere exchded. For evidence of the "shock" view of money demand, see $\mathrm{R}$. W. Hafer and Scott E. Hein, "The Dynanics and Estimation of Short-Rum Money Demand," this Reciow (Marcb 1980), pp. 26-35. By definition, these shock variables should not be correlated with the included independent variables. The out-of-sanmple simulation results to be reported later in this paper indicate that there is little evidence of a significant bias in these simulations.

${ }^{14}$ See Frank de Leeww and John Kalchbrenner, "Monetary and Fiscal Actions: A Test of Their Relative Impontance in Economic Stabilization - Comment," this Review (April 1969), pp. 6-11.

1\% Christopher A. Sims "Exogeneity and Causal Ordering in Macroeconomic Models" in New Methods in Business Cycle Research: Proceedings from a Conference (Federal Reserve Bank of Minneapolis, 1977), pp. 23-44. independent variable are not different from zero, the null hypothesis of exogeneity is supported. On the other hand, statistical significance of leading coeffcients suggests that simultaneous equation bias problems would result if the equation were estimated with ordinary least squares.

To test for the presence of simultaneous equation bias, four leads on both the fiscal and monetary variables were added to the basic equation as follows:

$$
\begin{aligned}
& \text { (2) } \quad \dot{\mathrm{Y}}_{i}=\mathrm{C}+\sum_{i=1}^{4} \mathrm{~m}_{1} \dot{\mathrm{M}}_{t-1}+\sum_{t=0}^{4} \mathrm{e}_{\mathrm{i}} \dot{\mathrm{E}}_{t-1}+\sum_{i=1}^{4} \mathrm{~m}_{i} \dot{\mathrm{M}}_{1-1} \\
& +\sum_{\mathrm{t}=1}^{4} \mathrm{e}_{i} \dot{\mathrm{E}}_{t+1}+\mathrm{H}_{\mathrm{t}} .
\end{aligned}
$$

Since the Sims test depends crucially on the statistical significance of regression coefficients, every effort was made to assure the absence of serially correlated error terms. This was accomplished by following Sims recommendation of filtering the data prior to estimation. In most cases, the filter employed was the first order linear filter ( $1-K L)$, where $\mathrm{L}$ is the lag operation and $K$ is a constant. The value of $K$ was determined by iterating over values from 0 to 1 , at intervals of 0.1 . The first value of $\mathrm{K}$ which yielded no evidence of a relationship between the contemporaneous residual and residuals lagged, first two and then four periods, was chosen as the appropriate value. ${ }^{13}$

This search procedure removed the problem of serially correlated disturbances in all relationships except that using old M1. In this case, the fourth lagged residual always remained statistically significant in an autoregressive error structure in the residuals. Thus, in the case of old $M 1$, the filter employed was $\left(1-K^{-4}\right)$.

Table 4 lists the F-statistics testing the null hypotheses; (1) $\mathrm{m}_{\mathrm{i}}^{\prime}=0$ for $\mathrm{i}=1,2,3,4 ;(2) \mathrm{e}=0$ for $\mathrm{i}=1,2,3,4$; and $(3) \mathrm{m}_{\mathrm{i}}^{\prime}=\mathrm{e}=0$ for $\mathrm{i}=1,2$, 3,4 . In none of the cases considered were F-statistics large enough to reject the null hypothesis at the 5 percent level, thus suggesting the absence of any simultaneous equation bias problems associated with the estimation results reported in table $2 .{ }^{1 t}$

\footnotetext{
${ }^{16}$ A similar search procedure was employed by Yash P. Mehra and David E. Spencer, "The St. Leus Equation and Reverse Causation: The Evidence Reexamined, Southern Economic fotmal (April 1979), pp. 1104-20.

1iThis conclusion is somewhat different than that obtained by Mehra and Spencer, "The St. Lonis Eutuation. . . ." Ira estimating a relationship similar to equation (1) they found evidence of simultaneons equation bias problems. However, their study differed in three important ways. First, the only
} 


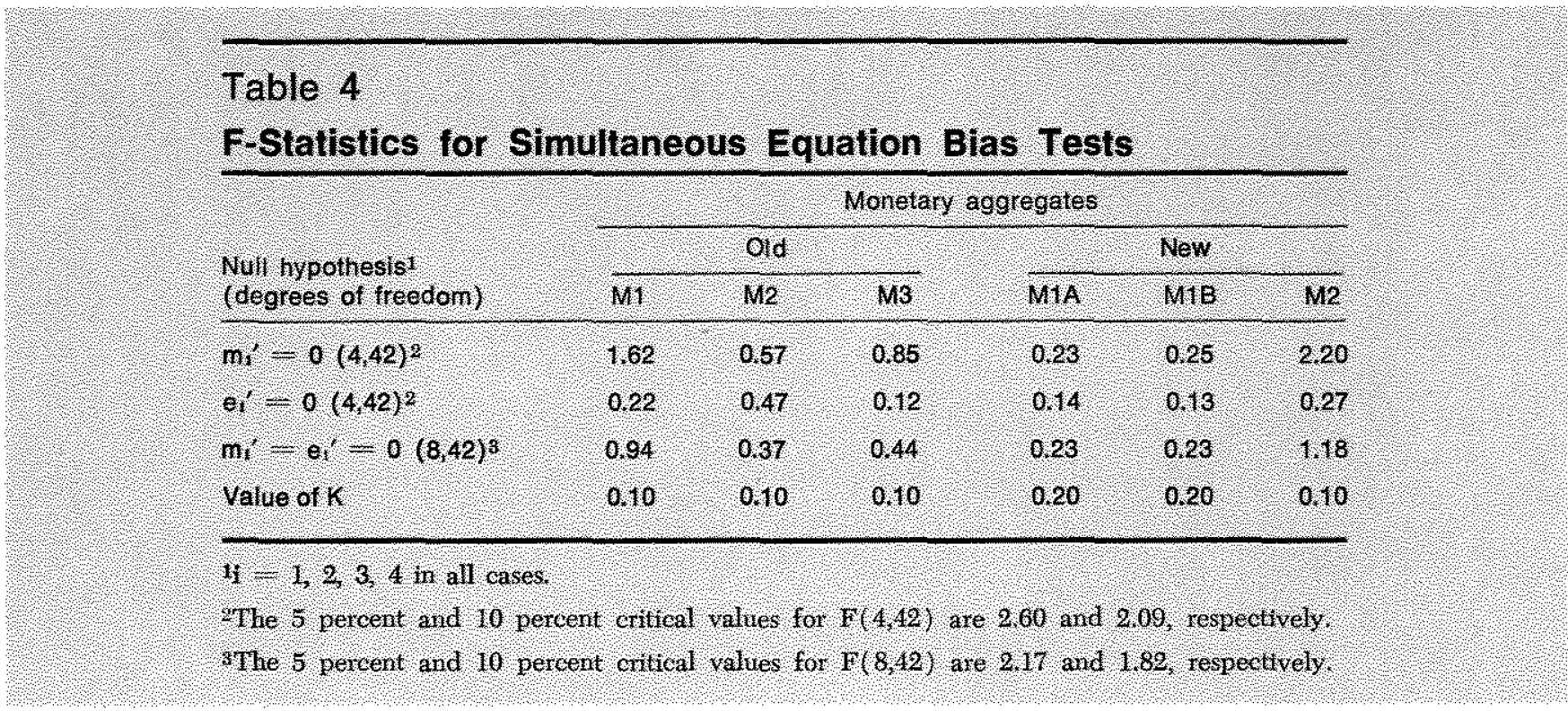

Two qualifications to this conclusion are required. These qualifications concern the regressions employ ing old M1 and new M2. While the F-statistics reported in table 4 do not allow the rejection of the null hypothesis at the 5 percent level, there were individual lead money coefficients in these two cases that were different from zero at certain levels of significance; thus, there is some evidence to reject the null hypothesis at lower significance levels. For example, in the case of old $\mathrm{Ml}$, the regression coefficient on the one-quarter lead of money was 0.64 . The $t-$ statistic associated with this individual coefficient was 2.32 , indicating that the estimate was statistically different from zero at the 5 percent level. In this regard, there is some evidence of "reverse causation" - an increase in economic activity "causing" an increase in future money growth. ${ }^{18}$ This result generates some concern about the regression estimates reported for the equation using old M1 in table 2.

It is interesting to note that the redefinitions of the monetary aggregates, although not directly concerned with this simultaneity problem, have done much to resolve it. None of the individual leading money coefficients were close to being statistically different from zero when the M1A aggregate was employed. Together, these findings suggest that the simultaneous

monetary variable they consider is the monetary base. Second, they include high-employment receipts, as well as highemployment expenditures, in their relationship. Finally, they focus on a different time period (I/1952-IV/1974)

1.8 More formally, if one were willing to use the 25 percent significance level, the null hypothesis that the leading M1 coefficients are equal to zero must be rejected. equation bias, to the extent it exists, is due to the inclusion of demand deposits held by foreign institutions or commercial banks.

In the case of new M2, the coefficient on the money variable led two quarters was -0.50 ; and its absolute t-statistic of 1.83 was significantly different from zero at the 10 percent level. In addition, the joint hypothesis that all leading money coefficients are zero had to be rejected at the 10 percent level. This again suggests the possibility of a simultaneous equation bias problem. However, it is important to recognize that the problem does not appear to be a result of a positive association between current economic activity and future money growth, as traditionally suggested. Rather, in this case, this regression coefficient suggests that current economic activity is negatively associated with new M2 growth two quarters in the future. ${ }^{19}$

This negative relationship should not come as a surprise in light of the evidence of the impact of disintermediation on new M2 growth. An increase in economic activity, by causing market interest rates to rise above Regulation $Q$ ceilings, will be associated, other things being equal, with a reduction in future new M2 growth.

In summary, it appears that the redefinitions of the

197x this regard, it is to be noted that wher old M3 is used, the coefficient on money variable led two quarters is also negative. However, the coefficient is not different from zero even at the 10 percent level. Thus, it appears that inclnding overnight RPs, overnight Eurodollars, and money market mutual funds in new M2 has compounded the simultaneity problem. 


\begin{tabular}{l} 
Table 5 \\
Summary Measures of Out-of-Sample \\
(IV/ $1977-\mathrm{IV} / 1979)$ GNP Predictions \\
\hline
\end{tabular}

$1 \mathrm{Need}$ not sum to unity as a result of rounding

monetary aggregates have removed possible problems associated with simultaneity as far as the narrow transaction aggregates are concerned. However, there still remains a question concerning simultaneity with regard to the more comprehensive measure.

\section{Prediction Results}

How well do the relationships presented in table 2 simulate nominal GNP over the IV/1977 through IV/1979 period? Table 5 indicates that the equation using the new M1B aggregate performs the best in simulating GNP growth over this period, regardless of the criteria considered. The strength of this equation is most evident in the lack of bias in the predictions. The other aggregates underpredict GNP growth over this period, on average, by approximately 2.5 percent. In comparison, the average prediction error for $\mathrm{M} 1 \mathrm{~B}$ is a trivial -0.02 percent.

It is also appropriate to note that the bias in prediction errors is smaller for new M1A than for old M1. Removing demand deposits held by foreign commercial banks and institutions did not reduce the variance of forecast error; it did, however, reduce the average error and the bias in the forecast.

The fact that the more comprehensive monetary aggregates (old M2, old M3, and new M2), which include savings deposits subjected to Regulation $Q$ ceilings, underpredict GNP growth by more than the transaction aggregates is again consistent with the view that disintermediation has adversely affected the growth of these deposits. The whole period from IV/1977 through IV/1979 has been characterized by market interest rates well above Regulation $Q$ ceilings. This has led to a relative slowing in the growth of these regulated deposits. As a result, equations using these aggregates have underpredicted economic activity since IV/1977.

\section{SUMMARY}

The monetary aggregates were redefined early this year. The purpose of this article was to examine these new aggregates in terms of their usefulness as monetary policy indicators. Two criteria for judging the usefulness of the monetary aggregates as indicators were suggested. First, to serve as an indicator, the aggregate should reflect the policy actions of the monetary authority and not be highly sensitive to nonpolicy influences. Second, the aggregate should be consistently and predictably related to economic activity.

Although the first criterion was not considered formally, examination of the rates of change of the new monetary aggregates indicated that redefining M2 did not remove the influence of nonpolicy forces. In particular, the movement of market interest rates relative to Regulation $Q$ ceilings has had an adverse effect on new M2 growth (relative to the narrowly defined aggregates), as it did with the old M2 and M3 aggregates. 
The second criterion was examined more extensively by regressing nominal GNP growth on the growth of the various monetary aggregates and a fiscal variable (growth rates of high-employment expenditures). These relationships were checked for structural stability, simultaneous equation bias, and out-of-sample prediction accuracy. Of the new monetary aggregates, only M2 showed any evidence of simultaneous equation bias. This problem is felt to be closely related to the impact of Regulation $Q$ ceilings. In out-ofsample simulations, M1B performed better than any of the other new aggregates analyzed, indicating that it had a closer relationship to economic activity than did the other new aggregates.

In light of the criteria suggested for judging the usefulness of the new monetary aggregates as mone- tary indicators, MlB was thus found to best satisfy these requirements. It appears to be relatively insensitive to nonpolicy influences (a characteristic it shares with M1A), and it is more predictably and consistently related to movements of nominal GNP than M1A or new M2.

On the other hand, new M2 was found to be particularly unreliable as a monetary indicator. Growth in this aggregate was found to be sensitive to nonpolicy forces. While proposed actions under the Financial Institutions Deregulation and Monetary Control Act of 1980 should eventually resolve this type of problem, new M2 growth will likely remain a poor monetary indicator in the seven-year transition period, especially in light of the absence of any reliable historical relationship with economic activity.

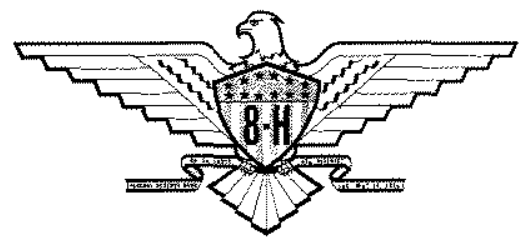

